\title{
Influence of implanted Mg concentration on defects and Mg distribution in GaN
}

Cite as: J. Appl. Phys. 128, 065701 (2020); https://doi.org/10.1063/5.0014717

Submitted: 21 May 2020 . Accepted: 04 August 2020 . Published Online: 14 August 2020

Ashutosh Kumar (D), Wei Yi, Jun Uzuhashi, Tadakatsu Ohkubo, Jun Chen (D), Takashi Sekiguchi, Ryo Tanaka (D), Shinya Takashima (D), Masaharu Edo, and Kazuhiro Hono (D)

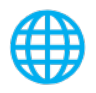

\section{ARTICLES YOU MAY BE INTERESTED IN}

Mg diffusion and activation along threading dislocations in $\mathrm{GaN}$

Applied Physics Letters 116, 242103 (2020); https://doi.org/10.1063/5.0009596

Screw dislocation that converts p-type GaN to n-type: Microscopic study on Mg condensation and leakage current in $\mathrm{p}-\mathrm{n}$ diodes

Applied Physics Letters 117, 012105 (2020); https://doi.org/10.1063/5.0010664

Growth of bulk GaN crystals

Journal of Applied Physics 128, 050902 (2020); https://doi.org/10.1063/5.0009900

\section{Lock-in Amplifiers up to $600 \mathrm{MHz}$}
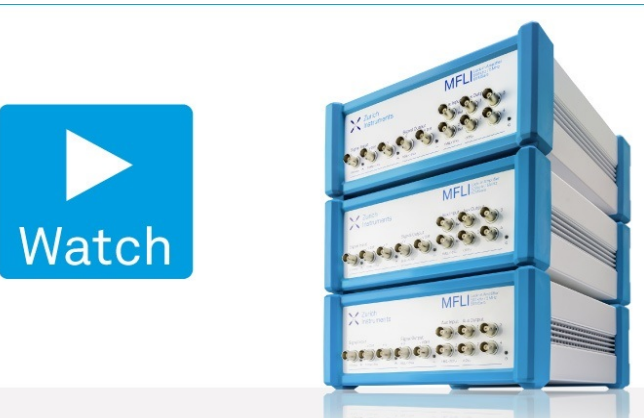


\title{
Influence of implanted Mg concentration on defects and Mg distribution in GaN
}

\author{
Cite as: J. Appl. Phys. 128, 065701 (2020); doi: 10.1063/5.0014717 \\ Submitted: 21 May 2020 - Accepted: 4 August 2020 . \\ Published Online: 14 August 2020
}

Ashutosh Kumar, ${ }^{1, a)}$ (D) Wei Yi, ${ }^{7}$ Jun Uzuhashi, ${ }^{7}{\text { Tadakatsu Ohkubo, }{ }^{7} \text { Jun Chen, }{ }^{1} \text { (D) Takashi Sekiguchi, }}^{{ }^{1}}$
Ryo Tanaka, ${ }^{2}$ (D) Shinya Takashima, ${ }^{2}$ (D) Masaharu Edo, ${ }^{2}$ and Kazuhiro Hono ${ }^{1}$ (D)

AFFILIATIONS

${ }^{7}$ National Institute for Materials Science, Tsukuba 305-0047, Japan

${ }^{2}$ Advanced Technology Laboratory, Fuji Electric Co., Ltd., Hino, Tokyo 191-8502, Japan

a) Author to whom correspondence should be addressed: Kumar.Ashutosh@nims.go.jp and akphyl@gmail.com

\begin{abstract}
Efficient acceptor activation in gallium nitride $(\mathrm{GaN})$ achieved through $\mathrm{Mg}$ ion-implantation depends mainly on the concentration of implanted $\mathrm{Mg}$ ions and the post-implantation annealing process. In this study, we conducted correlative scanning transmission electron microscopy, atom probe tomography, and cathodoluminescence (CL) measurements on Mg-implanted GaN layers with the implanted concentration ranging from $1 \times 10^{17} \mathrm{~cm}^{-3}$ to $1 \times 10^{19} \mathrm{~cm}^{-3}$. It was found that at the implanted concentration of $\sim 1 \times 10^{18} \mathrm{~cm}^{-3}, \mathrm{Mg}^{-1}$ atoms were randomly distributed with defects likely to be vacancy clusters whereas at the implanted concentration of $\sim 1 \times 10^{19} \mathrm{~cm}^{-3}$, $\mathrm{Mg}$-enriched clusters and dislocation loops were formed. From the CL measurements, the donor-acceptor pair (DAP) emissions from the implanted and un-implanted regions are obtained and then compared to analyze $\mathrm{Mg}$ activation in these regions. In the sample with $\mathrm{Mg} \sim 1 \times 10^{19} \mathrm{~cm}^{-3}$, the existence of Mg-enriched clusters and dislocations in the implanted region leads to a weaker DAP emission, whereas the absence of $\mathrm{Mg}$-enriched clusters and dislocations in the sample with $\mathrm{Mg} \sim 1 \times 10^{18} \mathrm{~cm}^{-3}$ resulted in a relatively stronger DAP emission.
\end{abstract}

Published under license by AIP Publishing. https://doi.org/10.1063/5.0014717

\section{INTRODUCTION}

Gallium nitride (GaN)-based materials have attracted much research interest in the last couple of decades because of their proven potential in realizing energy-efficient devices for highpower, high-frequency, and solid-state lighting applications. ${ }^{1-7}$ However, the inefficient p-type conduction via Mg-doping has hindered the application of GaN technology. This is primarily attributed to $\mathrm{Mg}$ acting as a deep acceptor impurity in GaN resulting in low free hole concentrations. Therefore, high concentrations of $\mathrm{Mg}$ need to be incorporated to achieve high hole concentrations. ${ }^{8-11}$ It is widely known that incorporating a high amount of $\mathrm{Mg}$ often results in the formation of Mg-enriched defects and clusters, leading to a decrease in free hole concentrations. ${ }^{12-14}$ Attempts have been made to understand the formation of such defects and their atomic structures in Mg-doped GaN layers, where $\mathrm{Mg}$ is incorporated during $\mathrm{GaN}$ growth via metalorganic chemical vapor deposition (MOCVD) or molecular beam epitaxy (MBE). ${ }^{12,15-18}$ However, versatile designing and processing of GaN-based modern devices requires selective-area doping to achieve precise local control over p-type conduction. In a typical GaN-based power device, the high-doped p-type regions are needed as contacts and hole transport layers, while the low-doped regions are needed for inversion channels. Such requirements can be fulfilled through ionimplantation that offers precise control of depth profiles at the desired local regions and is also a mature fabrication technology used in Si power devices. Therefore, Mg-incorporation in GaN via ion-implantation needs to be explored for further advancement and commercialization of GaN-based power devices.

Although attempts have been made to realize $\mathrm{p}-\mathrm{GaN}$ via $\mathrm{Mg}$ ion-implantation, achieving efficient p-type conductivity through this route remains a challenge. ${ }^{19-29}$ The success of this route mainly depends upon finding the optimum conditions, i.e., the concentration of $\mathrm{Mg}$ ions, choice of protection layer, and post-implantation annealing temperature. This high-temperature annealing of the Mg-implanted GaN layers with commonly used protection layers of $\mathrm{SiO}_{2}, \mathrm{Si}_{3} \mathrm{~N}_{4}$, and $\mathrm{AlN}$ removes the crystal damages induced due to ion-implantation and facilitates the migration of $\mathrm{Mg}$ 
atoms to the desired substitutional Ga sites. Various annealing approaches have been reported such as conventional rapid thermal annealing, ${ }^{20,21}$ multicycle rapid thermal annealing, ${ }^{22,29}$ and annealing under high $\mathrm{N}_{2}$ pressure $^{26,27}$ at temperatures usually higher than $1000^{\circ} \mathrm{C}$. However, such thermal treatments lead to the diffusion of donor-like impurities from the protection layer into $\mathrm{GaN}$. In addition, donor-type defects such as $\mathrm{N}$ vacancies are also introduced during ion-implantation. Based on the photoluminescence measurements, Kojima et al. ${ }^{30}$ suggested that such $\mathrm{N}$ vacancies act as the deep donor in GaN. These donor-like impurities and $\mathrm{N}$ vacancies compensate for the acceptors and inhibit $\mathrm{Mg}$ activation. Another issue in $\mathrm{Mg}$ activation is the formation of $\mathrm{Mg}$-enriched defects due to the interactions of vacancy-type defects with the implanted $\mathrm{Mg}$ ions as investigated via positron annihilation spectroscopy (PAS). ${ }^{31,32}$ Recently, we conducted a systematic study to understand the impact of post-implantation annealing on the formation of Mg-enriched defects via scanning transmission electron microscopy (STEM) and atom probe tomography (APT). ${ }^{33}$ The concentration of implanted $\mathrm{Mg}$ ions was fixed at $\sim 1 \times 10^{19} \mathrm{~cm}^{-3}$. We found that $\mathrm{Mg}$ clusters are formed during post-implantation annealing above $1000^{\circ} \mathrm{C}$ and dislocation loops appear at an annealing temperature of $1300^{\circ} \mathrm{C}$. However, it is reported that annealing behavior also depends on the implanted Mg-ion concentrations because the tendency of agglomeration of the vacancytype defects increases with increasing $\mathrm{Mg}$ concentrations at a fixed annealing temperature. ${ }^{31}$ Therefore, it is important to investigate the nature of defects in GaN layers implanted with varying concentrations of $\mathrm{Mg}$ ions at a fixed post-implantation annealing temperature; such investigations can help to separate the effect of implanted $\mathrm{Mg}$ and post-implantation annealing on the formation of $\mathrm{Mg}$-enriched defects and $\mathrm{Mg}$ activation. For this purpose, we prepared $\mathrm{GaN}$ layers implanted with three different concentrations of $\mathrm{Mg}$ ions, i.e., $1 \times 10^{17} \mathrm{~cm}^{-3}, 1 \times 10^{18} \mathrm{~cm}^{-3}$, and $1 \times 10^{19} \mathrm{~cm}^{-3}$, all of which were annealed at $1300^{\circ} \mathrm{C}$ after implantation. In order to understand how the different concentrations of the implanted $\mathrm{Mg}$ ions influence the $\mathrm{Mg}$ activation, we observed cathodoluminescence $(\mathrm{CL})$ measurements from the cross-sectional specimens.

\section{METHODS}

$\mathrm{Mg}$ ion-implantation was carried out in $4 \mu \mathrm{m}$-thick not intentionally doped GaN epitaxial layers grown by MOCVD on free standing $\mathrm{GaN}$ substrates oriented along the c-axis. These substrates were grown using hydride vapor phase epitaxy. The $\mathrm{Mg}$ ions were implanted at room temperature into these not intentionally doped $\mathrm{GaN}$ layers for the purpose of fabricating GaN-based vertical power devices. We intend to use these MOCVD-grown layers as drift layers from the viewpoint of controlling carrier concentrations. $\mathrm{Mg}$ ions were implanted at various energies ranging from 20 to $430 \mathrm{keV}$ to obtain $\mathrm{Mg}$ concentrations of $1 \times 10^{17}, 1 \times 10^{18}$, and $1 \times 10^{19} \mathrm{~cm}^{-3}$ in the form of a $500 \mathrm{~nm}$-deep box profile. Following this, a $300 \mathrm{~nm}$-thick AlN layer acting as the decomposition shield was sputtered. All the samples with different $\mathrm{Mg}$ concentrations were annealed at $1300^{\circ} \mathrm{C}$ for $5 \mathrm{~min}$ followed by chemical removal of the AlN layer. The annealing rate and environment are the same as those of our earlier work. ${ }^{33}$ An aberration-corrected electron microscope (FEI Titan G2 80-200) operating at $200 \mathrm{kV}$ and a local electrode atom probe (CAMECA LEAP 5000XS) were used for STEM and APT measurements, respectively. For the STEM and APT measurements, thin-film and needle-shaped specimens were prepared by a focused ion beam milling-based standard lift-out method, using a FEI Helios G4UX dual beam system. For reducing the damages caused by Ga ions and ensuring a high quality of the prepared specimens, low accelerating voltages of $\sim 2-5 \mathrm{kV}$ were used in the final cleaning steps. APT tips were prepared along the c-axis. The APT measurements were conducted using pulsed UV laser $(355 \mathrm{~nm})$ excitation under ultrahigh vacuum conditions at the specimen temperature of $30 \mathrm{~K}$, a laser frequency of $250 \mathrm{kHz}$, and the evaporation rate of $1.0 \%$. The laser energy of $10 \mathrm{fJ}$ was used as the stoichiometric $\mathrm{Ga}: \mathrm{N}$ ratio close to $1: 1$ was obtained at this energy. The obtained APT data were reconstructed using the CAMECA Integrated Visualization and Analysis Software to obtain a three-dimensional view of the specimen. For the CL measurements, cross-sectional specimens were prepared by a novel angle cutting method, the details of which are described elsewhere. ${ }^{19,34}$ The CL measurements were conducted using a HORIBA MP32 CL system attached to a Hitachi SU6600 field emission scanning electron microscope (FESEM) at an incident energy of $3 \mathrm{kV}$ and a specimen temperature of $78 \mathrm{~K}$.

\section{RESULTS AND DISCUSSION}

Figure 1 shows $\mathrm{Mg}$ concentration profiles of the three samples measured via secondary ion mass spectrometry (SIMS). The $\mathrm{Mg}$ concentration is found to be $1 \times 10^{17}, 1 \times 10^{18}$, and $1 \times 10^{19} \mathrm{~cm}^{-3}$, in the form of $500 \mathrm{~nm}$-deep box profiles. Microstructural investigations were conducted via low-angle annular dark-field scanning transmission electron microscopy (LAADF-STEM) as shown in Fig. 2. The imaging is conducted at the collection angle range of $32-193 \mathrm{mrad}$, which is lower than the typical angle range used in a

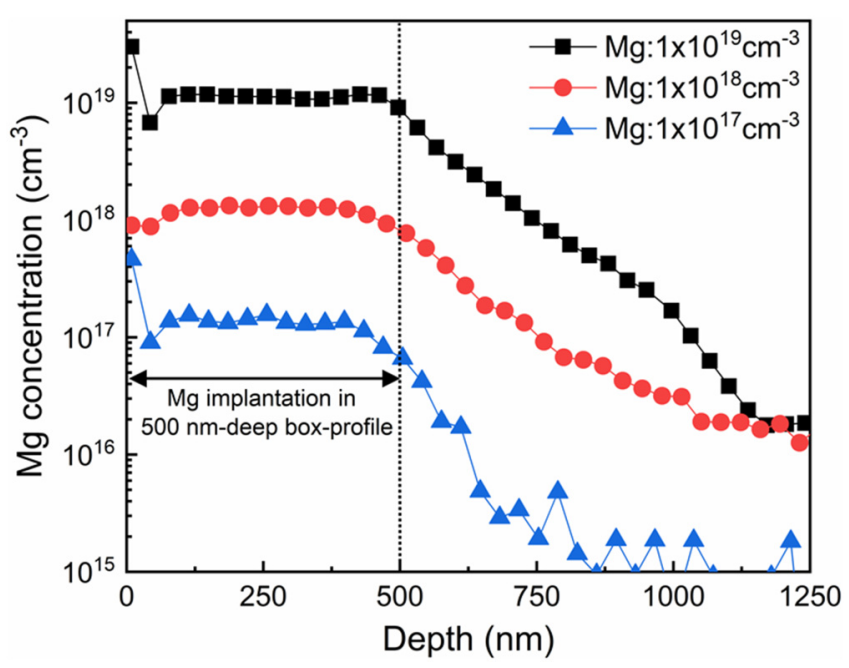

FIG. 1. SIMS profiles of Mg concentrations in the form of $500 \mathrm{~nm}$-deep box for Mg-implanted GaN samples with implanted Mg concentrations of $1 \times 10^{17}$, $1 \times 10^{18}$, and $1 \times 10^{19} \mathrm{~cm}^{-3}$. 

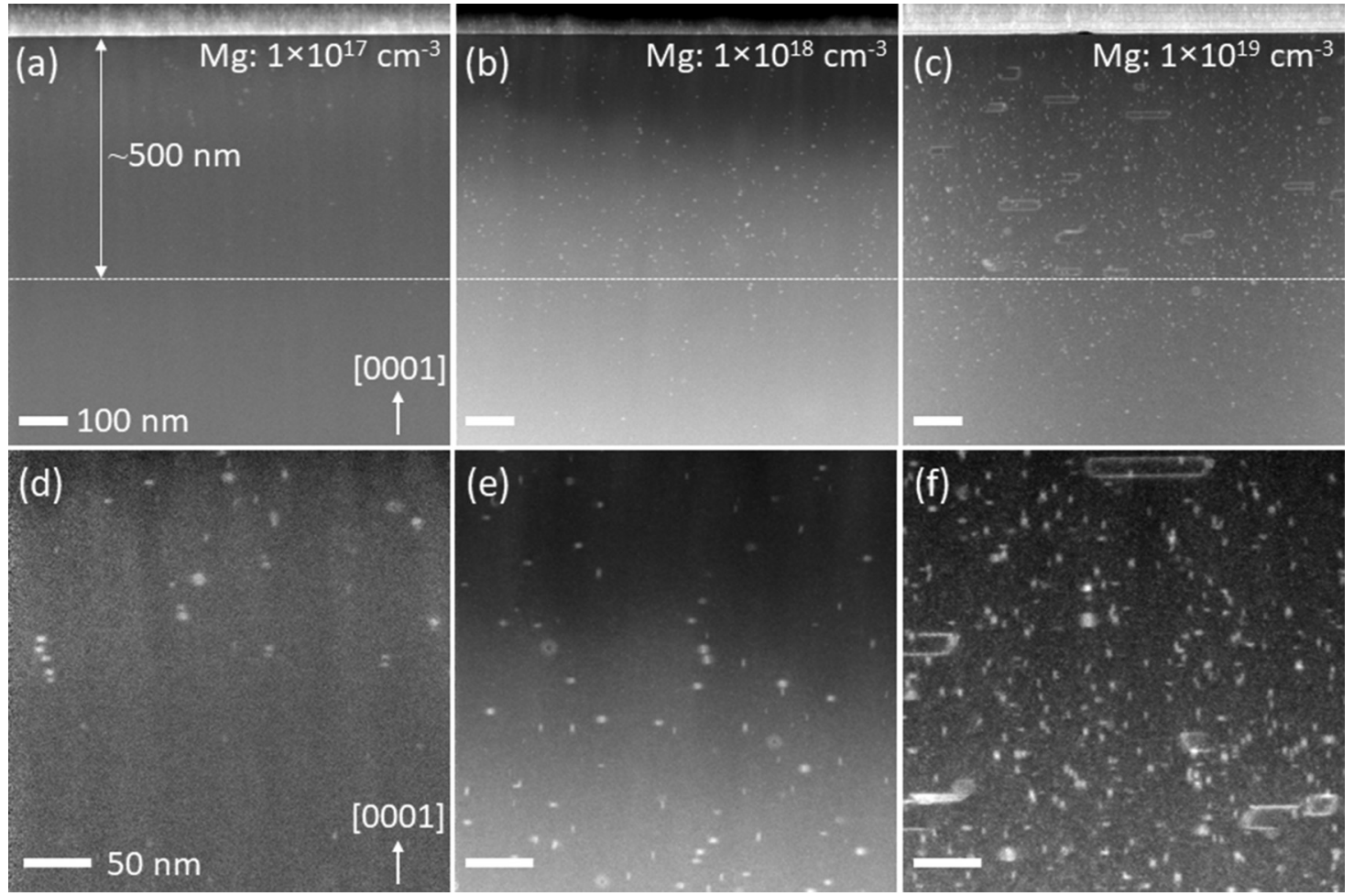

FIG. 2. LAADF-STEM images of Mg-implanted GaN samples with implanted Mg concentrations of (a) $1 \times 10^{17}$, (b) $1 \times 10^{18}$, and (c) $1 \times 10^{19} \mathrm{~cm}^{-3}$, where (d), (e), and (f) show the magnified views, respectively.

high-angle annular dark-field scanning transmission electron microscopy (HAADF-STEM). Although less commonly used compared to HAADF-SETM, the use of LAADF-STEM for imaging defects is reported to minimize the effect of Z-contrast and enhance diffraction contrast. ${ }^{35-37}$ In our observations, [11 20$]$ is chosen as the viewing direction. The vacancy-type defects, their complexes, or clusters distort the lattice and induce strain fields. These strain fields give rise to bright contrasts in the LAADF-STEM images as shown in Fig. 2. Muller et al. $^{35}$ also observed similar bright contrasts surrounding oxygen vacancies in LAADF-STEM imaging and attributed it to strain fields. In fact, they found LAADF-STEM to be a better option for imaging such contrasts compared to HAADF-STEM. A dotted line at the depth of $500 \mathrm{~nm}$ from the top surface is drawn for comparison with the SIMS Mg profile in Fig. 1. In the sample implanted with $\mathrm{Mg} \sim 1 \times 10^{17} \mathrm{~cm}^{-3}$, the defects appear up to an approximate depth of $200 \mathrm{~nm}$ [Fig. 2(a)], whereas the defects can be clearly observed up to a depth of $500 \mathrm{~nm}$ in the sample implanted with $\mathrm{Mg} \sim 1 \times 10^{18} \mathrm{~cm}^{-3}$ [Fig. 2(b)]. In the sample implanted with $\mathrm{Mg} \sim 1 \times 10^{19} \mathrm{~cm}^{-3}$, the defects appear clearly beyond $500 \mathrm{~nm}$ as shown in Fig. 2(c). In the SIMS depth profile for implanted $\mathrm{Mg} \sim 1 \times 10^{19} \mathrm{~cm}^{-3}$ (see Fig. 1), the $\mathrm{Mg}$ concentration starts to decrease beyond the depth of $500 \mathrm{~nm}$ and the LAADF-STEM image [Fig. 2(c)] reveals the absence of loop-like features in this region. The defects appearance beyond $500 \mathrm{~nm}$ in this sample is similar to defects appearing within the depth of $500 \mathrm{~nm}$ in the sample with $\mathrm{Mg} \sim 1 \times 10^{18} \mathrm{~cm}^{-3}$ [Fig. 2(b)]. This suggests that the nature of the defects depends on the concentration of $\mathrm{Mg}$ ions implanted in the $\mathrm{GaN}$ samples annealed at the same temperature of $1300^{\circ} \mathrm{C}$.

From the LAADF-STEM images, the defect density appears to increase with the increase in $\mathrm{Mg}$ ions implanted as shown in Fig. 2. The ion-implantation-induced defects in GaN usually increase with the increasing concentration of the implanted ions as investigated by the various techniques like Rutherford backscattering/channeling, ${ }^{38-40}$ TEM, ${ }^{38-42}$ and $\mathrm{x}$-ray diffraction. ${ }^{41,42}$ Since the apparent defect density varies depending on the thickness of the TEM specimen, the thickness calibrations have been conducted via electron energy-loss spectroscopy (EELS). ${ }^{43}$ EELS was conducted for the needle-shaped GaN specimen because the thickness $(t)$ is the same as the diameter. From the zero-loss peak intensity $\left(I_{0}\right)$ and low-loss intensity $\left(I_{l}\right)$ obtained from the EELS spectrum and $t$ measured from the TEM image, the average mean free path $(\lambda)$ for $\mathrm{GaN}$ was calculated to be 0.12 using $\lambda=t /\left[\ln \left(\frac{I_{l}}{I_{0}}\right)\right]$. Following this, EELS signals are obtained from the TEM specimens shown in Figs. 2(a)-2(c), and using $I_{0}, I_{l}$, and $\lambda$ $(=0.12)$, the thicknesses of the TEM specimens are correctly determined as a function of the depth. The thicknesses of the prepared TEM specimens were found to vary from the surface to a depth of $700 \mathrm{~nm}$. The thickness varied from 91 to $113 \mathrm{~nm}, 45$ to $130 \mathrm{~nm}$, and 


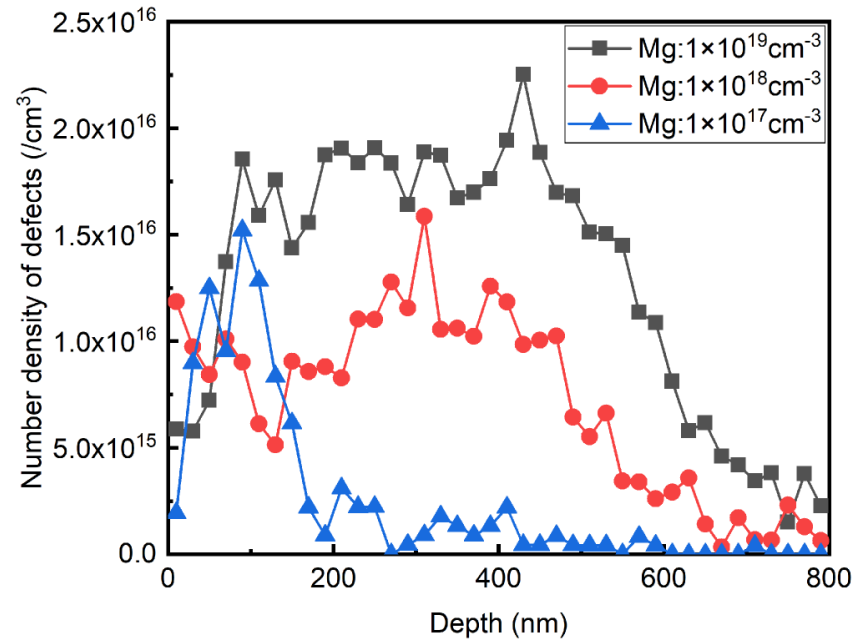

FIG. 3. The variation of the number density of defects as a function of depth at varying concentrations of implanted Mg. As the thickness of the prepared TEM specimen affects the appearance of defects, EELS-based thickness calibrations have been conducted.
82 to $115 \mathrm{~nm}$ for the samples with the implanted Mg-concentrations of $1 \times 10^{17}, 1 \times 10^{18}$ and $1 \times 10^{19} \mathrm{~cm}^{-3}$, respectively. Once the depthdependent thickness is known, the number density of the defects (including loop-like features) with depth is determined as shown in Fig. 3. It is found to be increasing with the increasing concentrations of the implanted $\mathrm{Mg}$ ions. Using PAS, Uedono et. al. ${ }^{31}$ characterized vacancy-type defects in the Mg-implanted GaN layers under similar conditions as that those of the present study, i.e., Mg-concentrations of $1 \times 10^{17}, 1 \times 10^{18}$, and $1 \times 10^{19} \mathrm{~cm}^{-3}$ and an annealing temperature of $1300^{\circ} \mathrm{C}$. They found that the ion-implantation of $\mathrm{Mg}$ resulted in the formation of $\mathrm{Ga}$ vacancies $\left(\mathrm{V}_{\mathrm{Ga}}\right), \mathrm{N}$ vacancies $\left(\mathrm{V}_{\mathrm{N}}\right)$, and their complexes. A complex of $\mathrm{V}_{\mathrm{Ga}}$ and $V_{N}$ was reported to be the major defects in the as-implanted samples. The post-implantation annealing above $1000^{\circ} \mathrm{C}$ caused the major-defect species to agglomerate, resulting in the formation of vacancy clusters. As the samples investigated in this study are annealed at $1300^{\circ} \mathrm{C}$, the bright features observed in the LAADF-STEM images are likely to be the agglomerated vacancy clusters. On increasing the concentration of implanted $\mathrm{Mg}$, the number of vacancies and their agglomeration increases, explaining the increasing number densities of defects with the increasing concentrations of implanted $\mathrm{Mg}$.
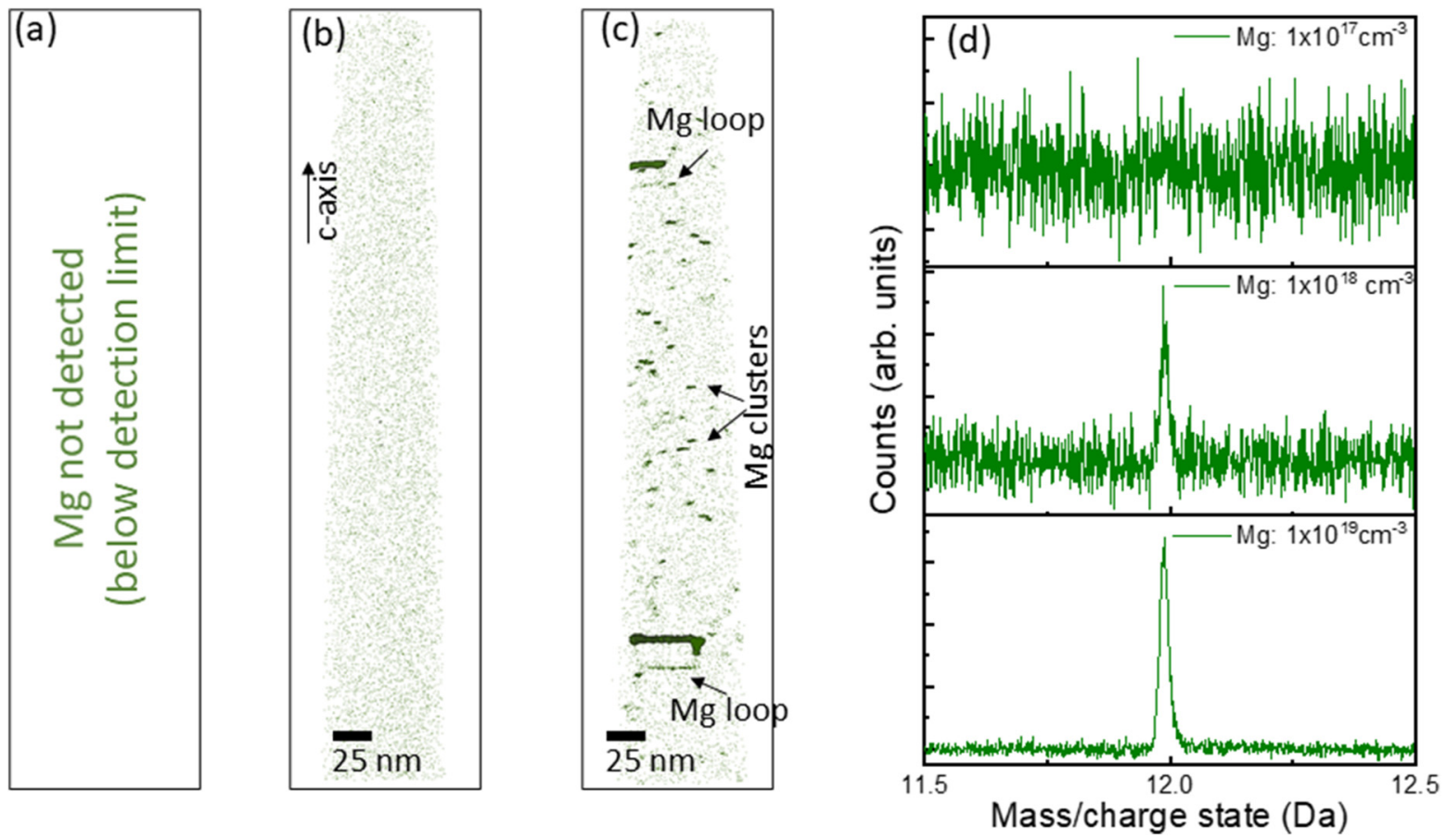

FIG. 4. Reconstructed APT maps of Mg for samples implanted with Mg concentrations of (a) $1 \times 10^{17}$, (b) $1 \times 10^{18}$, and (c) $1 \times 10^{19} \mathrm{~cm}^{-3}$. Mg is not detected in (a), while (b) and (c) are presented at an iso-concentration surface of 0.8 at. \%. The Mg mass spectra corresponding to (a), (b), and (c) are shown in (d), where Mg peaks are clearly observed in samples implanted with $\mathrm{Mg}$ concentrations of $1 \times 10^{18}$ and $1 \times 10^{19} \mathrm{~cm}^{-3}$. 
From the microstructural analysis, it is clear that the number density of defects and their distribution in GaN depends upon the level of implanted $\mathrm{Mg}$ ions. To further understand this dependence, APT analyses have been conducted and the reconstructed three-dimensional $\mathrm{Mg}$-atom maps have been obtained where the $\mathrm{Mg}$ concentrations of the samples are $1 \times 10^{17}, 1 \times 10^{18}$, and $1 \times 10^{19} \mathrm{~cm}^{-3}$, shown in Figs. 4(a)-4(c), respectively. In the APT maps, $\mathrm{Mg}$ iso-concentration surfaces of 0.8 at. \% are drawn. The corresponding mass spectra of $\mathrm{Mg}$ are shown in Figs. 4(d). For the sample with the $\mathrm{Mg}$ concentration of $1 \times 10^{17} \mathrm{~cm}^{-3}, \mathrm{Mg}$ could not be detected, possibly due to the detection limit of LEAP. In other samples, Mg amounts evaluated by the APT analysis are found to be approximately 0.001 and 0.012 at. \% that correspond to $1 \times 10^{18}$ and $1 \times 10^{19} \mathrm{~cm}^{-3}$, respectively. These values are close to the expected $\mathrm{Mg}$ concentrations of $1 \times 10^{18}$ and $1 \times 10^{19} \mathrm{~cm}^{-3}$, based on the SIMS measurements (see Fig. 1). In the sample with the $\mathrm{Mg}$ concentration of $\sim 1 \times 10^{18} \mathrm{~cm}^{-3}, \mathrm{Mg}$ appears to be randomly distributed as depicted in Fig. 4(b), with no evidence of Mg clustering, whereas Mg-rich features in the form of clusters and loops are observed in the sample with the $\mathrm{Mg}$ concentration of $\sim 1 \times 10^{19} \mathrm{~cm}^{-3}$, as shown in Fig. 4(c). The appearance of loop-like features is consistent with the LAADF-STEM observation, where similar loop-like features are observed [see Figs. 2(c) and 2(f)]. High-resolution STEM images of a typical Mg-enriched cluster and loop are shown in our recent work. ${ }^{33}$ These dislocation loops tend to have different levels of $\mathrm{Mg}$ enrichment on their opposite sides; $\mathrm{Mg}$ concentrations in these loops were found to be in the range of $2 \times 10^{20}-5 \times 10^{21} \mathrm{~cm}^{-3}$, with a possibility of $\mathrm{Mg}$ substituting $\mathrm{Ga}$ at these loops. ${ }^{33}$

To confirm the randomness of $\mathrm{Mg}$ distribution, we have conducted a frequency distribution analysis of $\mathrm{Mg}$ atoms by dividing the analyzed APT volume into blocks of 500 atoms. The experimentally obtained $\mathrm{Mg}$ distribution is then compared with the binominal distribution which is expected for the random occurrence of $\mathrm{Mg}$ atoms, as shown in Fig. 5. The $\mathrm{Mg}$ distribution in the sample with the $\mathrm{Mg}$ concentration of $\sim 1 \times 10^{18} \mathrm{~cm}^{-3}$ follows a binomial distribution, indicating the random distribution of $\mathrm{Mg}$, whereas a significant shift away from the binomial distribution in the sample with the $\mathrm{Mg}$ concentration of $\sim 1 \times 10^{19} \mathrm{~cm}^{-3}$ suggests that $\mathrm{Mg}$ atoms are clustered. Therefore, the defects observed via LAADF-STEM in the sample with $\mathrm{Mg} \sim 1 \times 10^{18} \mathrm{~cm}^{-3}$ are not likely to be $\mathrm{Mg}$ clusters. Note that the analyzed APT volume is less than that observed by TEM analysis. If the number density of $\mathrm{Mg}$ clusters is very small, there is a possibility that no defects were included within the analyzed volume in Fig. 4(b). Therefore, we quantitatively estimated the number of $\mathrm{Mg}$ clusters expected in the analyzed volume in Fig. 4(b). If all defects $\left(\sim 1 \times 10^{16} \mathrm{~cm}^{-3}\right)$ observed by LAADF-STEM analysis in this sample are assumed to be $\mathrm{Mg}$ clusters, one can expect about $20 \mathrm{Mg}$ clusters in the APT-reconstructed volume in Fig. 4(b). However, not even a single $\mathrm{Mg}$ cluster is observed, indicating that almost all the defects in the sample implanted with $\mathrm{Mg} \sim 1 \times 10^{18} \mathrm{~cm}^{-3}$ are vacancy clusters.

These correlative findings of STEM and APT are used to understand the donor-acceptor pair (DAP) emissions from these samples. The monochromatic CL images of the DAP emission for all the three samples are shown in Fig. 6. The existence of DAP emission is usually linked to $\mathrm{Mg}$ activation, i.e., the formation of $\mathrm{Mg}_{\mathrm{Ga}}$ acceptors. Compared with the DAP emissions from the $\mathrm{Mg}$-implanted regions of the samples with $\mathrm{Mg}$ concentrations of
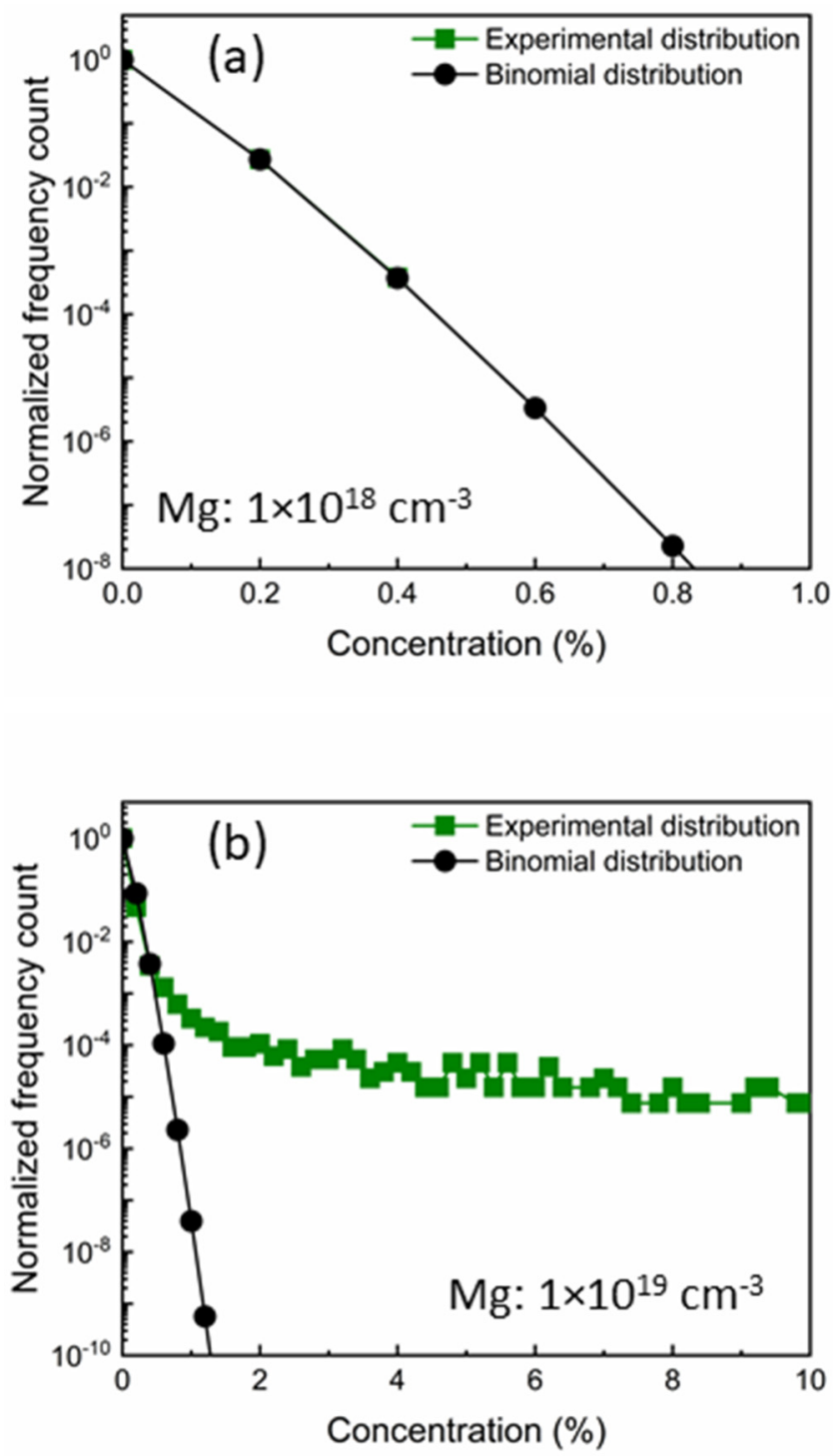

FIG. 5. Frequency distribution analysis conducted by dividing APT volume into blocks of 500 atoms for samples implanted with $\mathrm{Mg}$ concentrations of (a) $1 \times 10^{18}$ and (b) $1 \times 10^{19} \mathrm{~cm}^{-3}$. The comparison between the experimentally obtained $\mathrm{Mg}$ distribution and theoretical binomial distribution suggests that $\mathrm{Mg}$ atoms are randomly distributed for the sample implanted with $\mathrm{Mg} \sim 1 \times 10^{18}$ $\mathrm{cm}^{-3}$ and clustered for the sample implanted with $\mathrm{Mg} \sim 1 \times 10^{19} \mathrm{~cm}^{-3}$.

$1 \times 10^{17}$ and $1 \times 10^{18} \mathrm{~cm}^{-3}$, a weaker DAP emission is observed in the sample implanted with $\mathrm{Mg} \sim 1 \times 10^{19} \mathrm{~cm}^{-3}$. This suggests that $\mathrm{Mg}$ is not effectively activated in the implanted region (up to a depth of $500 \mathrm{~nm}$ ) and a large number of defects behave as nonradiative recombination centers in this region. However, this sample shows a relatively stronger DAP emission beneath the implanted layer (approximately beyond $500 \mathrm{~nm}$ ) as shown in Fig. 6(c). The CL spectra from different regions of this sample are shown elsewhere. ${ }^{19}$ 

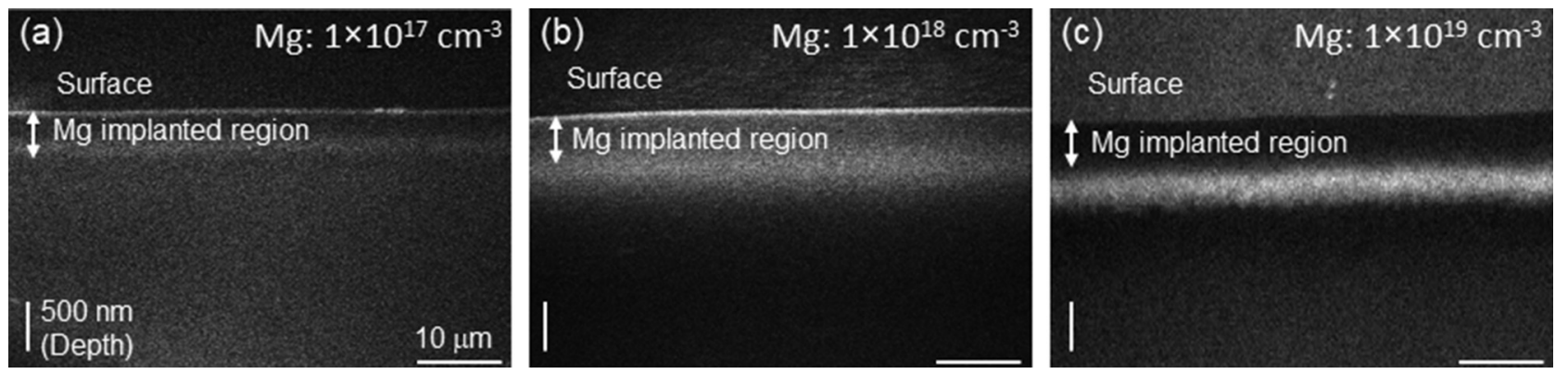

FIG. 6. Monochromatic CL images taken at DAP emission ( $380 \mathrm{~nm}$ ) in GaN samples implanted with Mg concentrations of (a) $1 \times 10^{17}$, (b) $1 \times 10^{18}$, and (c) $1 \times 10^{19} \mathrm{~cm}^{-3}$. The $500 \mathrm{~nm}$ vertical bar shows the actual depth calculated from the beveled cutting angle.

The presence of Mg-enriched clusters and loops in this sample may also affect the energy at which DAP emission is observed. For this, CL spectra of all the three samples are compared as shown in Fig. 7. For the samples with $\mathrm{Mg}$ concentrations of $1 \times 10^{17}$ and $1 \times 10^{18} \mathrm{~cm}^{-3}$, DAP emission is observed at $3.28 \mathrm{eV}$. For the sample with the $\mathrm{Mg}$ concentration of $1 \times 10^{19} \mathrm{~cm}^{-3}$, a comparatively weak DAP emission is observed, with the red-shift of about $0.1 \mathrm{eV}$ that is attributed to the lattice strain induced due to the presence of Mg-enriched clusters and loops. The CL behavior of the sample implanted with $\mathrm{Mg} \sim 1 \times 10^{19} \mathrm{~cm}^{-3}$ is explained by comparing the number density of $\mathrm{Mg}$ clusters, as observed in the $\mathrm{Mg}$ atom map [Fig. 4(c)], with the number density of defects obtained from the LAADF-STEM analyses (Fig. 3). The number density of Mg clusters is carefully calculated from the reconstructed APT volume that increases with depth. For this, we divided the reconstructed volume

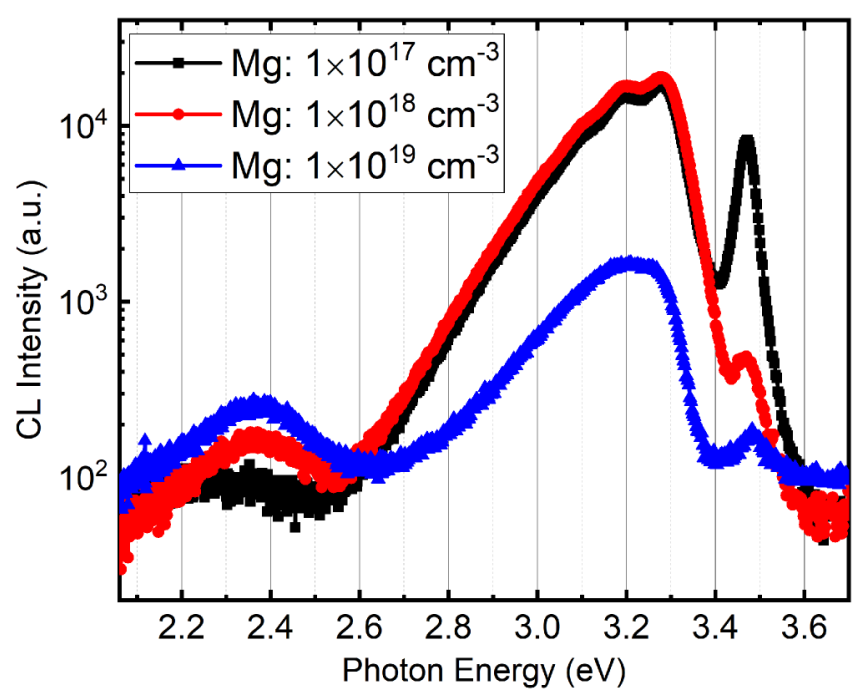

FIG. 7. CL spectra of the samples implanted with $\mathrm{Mg}$ concentrations of $1 \times 10^{17}, 1 \times 10^{18}$, and $1 \times 10^{19} \mathrm{~cm}^{-3}$.

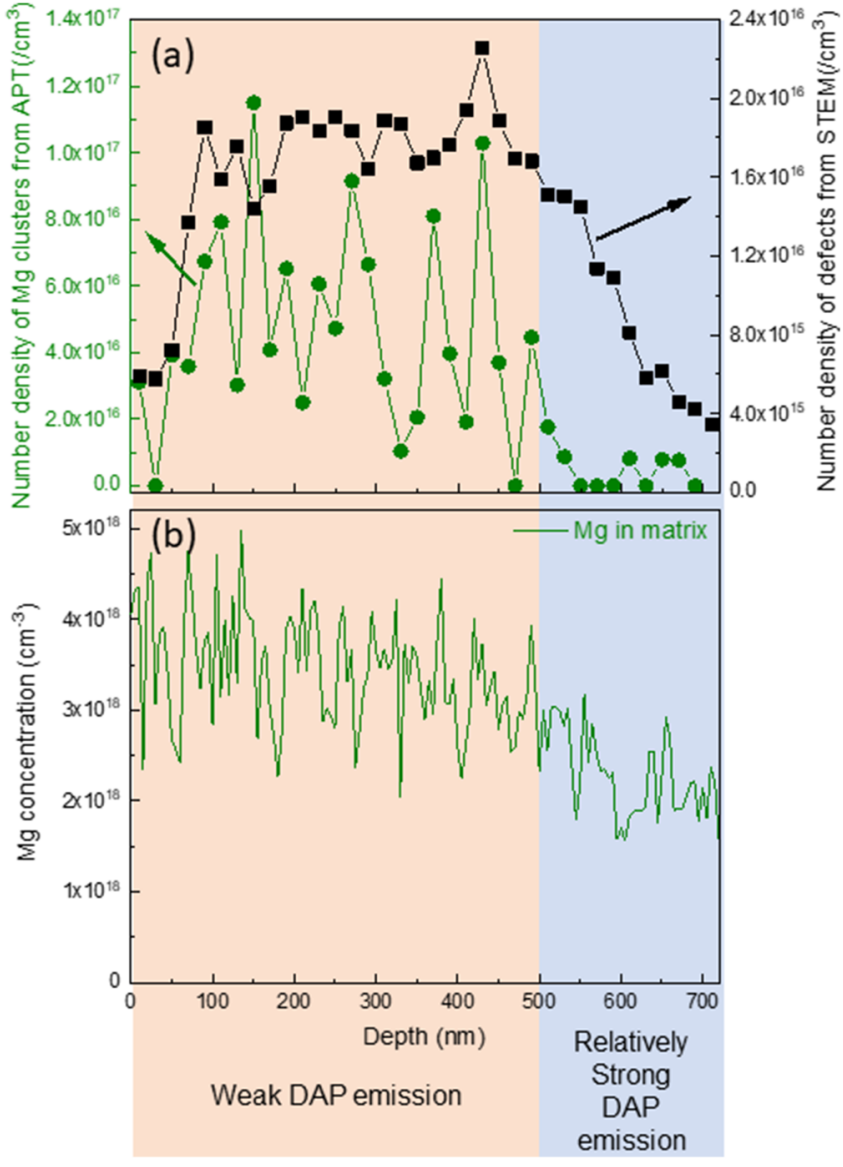

FIG. 8. (a) Comparative profiles of number densities of defects (obtained from STEM) and Mg clusters (obtained from APT) as a function of depth. (b) Variation in concentration of $\mathrm{Mg}$ with depth in the background $\mathrm{GaN}$ matrix. The different colors on either side of the $500 \mathrm{~nm}$ point indicate the implanted and un-implanted regions where different intensities of DAP emissions were observed. 
$(0-720 \mathrm{~nm})$ into $20 \mathrm{~nm}$-deep disks and calculated the number of $\mathrm{Mg}$ clusters in each disk. As the volume of each disk is known, the depth-dependent number density of $\mathrm{Mg}$ clusters is determined as shown in Fig. 8(a), and it is compared with the number density of defects obtained as a function of depth from the LAADF-STEM analyses, also shown in Fig. 8(a). The number density of Mg clusters (from APT) is found to be higher as compared with the number density of defects (from LAADF-STEM). Note that LAADF-STEM may underestimate the defect density as very tiny $\mathrm{Mg}$ clusters may not be contributing to the defects contrast, whereas APT can accurately detect such smaller $\mathrm{Mg}$ clusters. Therefore, we observed a higher number of Mg clusters in APT measurements, as compared with the defects from LAADF-STEM measurements. The appearance of $\mathrm{Mg}$ clusters and loops is clearly seen up to an approximate depth of $500 \mathrm{~nm}$ and drops significantly thereafter. Reportedly, these clusters are optically inactive ${ }^{44}$ and therefore explain the weak DAP emission from the Mg-implanted region. Beyond $500 \mathrm{~nm}$, a relatively strong DAP emission is observed that is attributed to the combined effect of the absence of Mg-enriched features and the presence of $\mathrm{Mg}$ in the background $\mathrm{GaN}$ matrix. To estimate the $\mathrm{Mg}$ concentration in the GaN matrix of this sample, the Mg-enriched clusters and loops observed in the APT reconstruction [Fig. 4(c)] were intentionally selected and removed using the CAMECA Integrated Visualization and Analysis Software (IVAS). Thereafter, the $\mathrm{Mg}$ concentration in the background matrix was obtained and its line profile as a function of depth is shown in Fig. 8(b). The estimated amount of $\mathrm{Mg}$ in the $\mathrm{GaN}$ matrix is found to be lying between $2.0 \times 10^{18}$ and $5.0 \times 10^{18} \mathrm{~cm}^{-3}$, up to a depth of $500 \mathrm{~nm}$. In the sample implanted with $\mathrm{Mg} \sim 1 \times 10^{18} \mathrm{~cm}^{-3}$, the $\mathrm{Mg}$ clusters and loops were not observed in the implanted region which resulted in a relatively strong DAP emission in comparison with the sample implanted $\sim 1 \times 10^{19} \mathrm{~cm}^{-3}$. However, vacancy clusters are observed in the implanted region of this sample as shown in the LAADF-STEM image [Fig. 2(b)]. This indicates that the vacancy clusters do not inhibit DAP emission as strongly as the Mg clusters do. Our findings suggest that the comparative analysis of the number density of vacancy clusters and $\mathrm{Mg}$ clusters as a function of depth can be used to explain DAP emissions from various regions of the samples with varying concentrations of implanted $\mathrm{Mg}$ ions. As the strength of DAP emission is dependent on $\mathrm{Mg}$ activation, the present study may help in improving $\mathrm{Mg}$ activation by further optimization of the implanted $\mathrm{Mg}$ concentrations and postimplantation annealing temperature.

\section{CONCLUSION}

STEM and APT-based correlative microstructural and atomic-level $\mathrm{Mg}$ distribution analyses have been carried out on Mg-implanted $\mathrm{GaN}$ layers with varying concentrations of implanted $\mathrm{Mg}$ ranging from $1 \times 10^{17}$ to $1 \times 10^{19} \mathrm{~cm}^{-3}$. The number density of defects and the atomic-level $\mathrm{Mg}$ distribution depend upon the concentration of implanted $\mathrm{Mg}$. On increasing the concentration from $1 \times 10^{17}$ to $1 \times 10^{19} \mathrm{~cm}^{-3}$, the number density of defects increases. At implanted $\mathrm{Mg}$ concentration of $\sim 1 \times 10^{18} \mathrm{~cm}^{-3}, \mathrm{Mg}$ distribution is random, while Mg clustering is observed in the sample with the Mg concentration of $1 \times 10^{19} \mathrm{~cm}^{-3}$. As $\mathrm{Mg}$ clustering is not observed in the sample with the $\mathrm{Mg}$ concentration of $\sim 1 \times 10^{18} \mathrm{~cm}^{-3}$, the defects observed in the LAADF-STEM images are considered to be vacancy clusters. The DAP emissions obtained through CL measurements are used to explain $\mathrm{Mg}$ activation in the implanted regions. In the sample with the $\mathrm{Mg}$ concentration of $\sim 1 \times 10^{19} \mathrm{~cm}^{-3}$, the existence of $\mathrm{Mg}$ clusters was confirmed through the APT analysis up to $500 \mathrm{~nm}$ depth, beyond which their density diminishes. The weak and strong DAP emissions from the implanted and un-implanted regions of this sample, respectively, suggest that $\mathrm{Mg}$ clustering leads to the non-activation of implanted Mg. The combined use of APT and STEM in the present work suggests that the Mg distribution as well as the formation of $\mathrm{Mg}$-enriched clusters and loops depends upon the concentration of implanted $\mathrm{Mg}$ ions. The Mg-enriched features inhibit $\mathrm{Mg}$ activation; therefore, their formation should be suppressed to achieve efficient $\mathrm{p}$-type conductivity.

\section{ACKNOWLEDGMENTS}

This research is supported by the Ministry of Education, Culture, Sports, Science and Technology (MEXT), Japan, through its "Program for research and development of next-generation semiconductor to realize energy-saving society" (Grant No. JPJ005357).

\section{DATA AVAILABILITY}

The data that support the findings of this study are available within the article.

\section{REFERENCES}

${ }^{1}$ H. Amano, Y. Baines, E. Beam, M. Borga, T. Bouchet, P. R. Chalker, M. Charles, K. J. Chen, N. Chowdhury, R. Chu, C. De Santi, M. M. De Souza, S. Decoutere, L. Di Cioccio, B. Eckardt, T. Egawa, P. Fay, J. J. Freedsman, L. Guido, O. Häberlen, G. Haynes, T. Heckel, D. Hemakumara, P. Houston, J. Hu, M. Hua, Q. Huang, A. Huang, S. Jiang, H. Kawai, D. Kinzer, M. Kuball, A. Kumar, K. B. Lee, X. Li, D. Marcon, M. März, R. McCarthy, G. Meneghesso, M. Meneghini, E. Morvan, A. Nakajima, E. M. S. Narayanan, S. Oliver, T. Palacios, D. Piedra, M. Plissonnier, R. Reddy, M. Sun, I. Thayne, A. Torres, N. Trivellin, V. Unni, M. J. Uren, M. Van Hove, D. J. Wallis, J. Wang, J. Xie, S. Yagi, S. Yang, C. Youtsey, R. Yu, E. Zanoni, S. Zeltner, and Y. Zhang, J. Phys. D Appl. Phys. 51, 163001 (2018).

${ }^{2}$ S. P. DenBaars, D. Feezell, K. Kelchner, S. Pimputkar, C.-C. Pan, C.-C. Yen, S. Tanaka, Y. Zhao, N. Pfaff, R. Farrell, M. Iza, S. Keller, U. Mishra, J. S. Speck, and S. Nakamura, Acta Mater. 61, 945 (2013).

${ }^{3}$ A. Kumar, R. Kashid, A. Ghosh, V. Kumar, and R. Singh, ACS Appl. Mater. Interfaces 8, 8213 (2016).

${ }^{4} \mathrm{~S}$. Li and A. Waag, J. Appl. Phys. 111, 071101 (2012).

${ }^{5}$ A. Kumar, M. Latzel, S. Christiansen, V. Kumar, and R. Singh, Appl. Phys. Lett. 107, 093502 (2015).

${ }^{6}$ T. J. Flack, B. N. Pushpakaran, and S. B. Bayne, J. Electron. Mater. 45, 2673 (2016).

${ }^{\mathbf{7}}$ A. Kumar, R. Kapoor, M. Garg, V. Kumar, and R. Singh, Nanotechnology 28, 26LT02 (2017).

${ }^{8}$ U. Wahl, L. M. Amorim, V. Augustyns, A. Costa, E. David-Bosne, T. A. L. Lima, G. Lippertz, J. G. Correia, M. R. da Silva, M. J. Kappers, K. Temst, A. Vantomme, and L. M. C. Pereira, Phys. Rev. Lett. 118, 095501 (2017).

${ }^{9}$ G. Alfieri, V. K. Sundaramoorthy, and R. Micheletto, J. Appl. Phys. 123, 205303 (2018).

${ }^{10}$ S. Nayak, M. Gupta, U. V. Waghmare, and S. M. Shivaprasad, Phys. Rev. Appl. 11, 014027 (2019).

${ }^{11}$ G. Miceli and A. Pasquarello, Phys. Rev. B 93, 165207 (2016). 
${ }^{12}$ N. Tetsuo, I. Nobuyuki, T. Kazuyoshi, K. Keita, and K. Tetsu, J. Appl. Phys. 124, 165706 (2018).

${ }^{13}$ P. Kozodoy, H. Xing, S. P. DenBaars, U. K. Mishra, A. Saxler, R. Perrin, S. Elhamri, and W. C. Mitchel, J. Appl. Phys. 87, 1832 (2000).

${ }^{14}$ A. Castiglia, J.-F. Carlin, and N. Grandjean, Appl. Phys. Lett. 98(21), 213505 (2011).

${ }^{15}$ A. Kumar, K. Mitsuishi, T. Hara, K. Kimoto, Y. Irokawa, T. Nabatame, S. Takashima, K. Ueno, M. Edo, and Y. Koide, Nanoscale Res. Lett. 13, 403 (2018).

${ }^{\mathbf{1 6}}$ J. E. Northrup, Appl. Phys. Lett. 82, 2278 (2003).

${ }^{17} \mathrm{P}$. Vennéguès, M. Leroux, S. Dalmasso, M. Benaissa, P. De Mierry, P. Lorenzini, B. Damilano, B. Beaumont, J. Massies, and P. Gibart, Phys. Rev. B 68, 235214 (2003).

${ }^{18}$ Z. Liliental-Weber, T. Tomaszewicz, D. Zakharov, J. Jasinski, and M. A. O’Keefe, Phys. Rev. Lett. 93, 206102 (2004).

${ }^{19}$ J. Chen, W. Yi, T. Kimura, S. Takashima, M. Edo, and T. Sekiguchi, Appl. Phys. Express 12, 051010 (2019).

${ }^{20}$ T. Niwa, T. Fujii, and T. Oka, Appl. Phys. Express 10, 091002 (2017).

${ }^{21}$ T. Narita, T. Kachi, K. Kataoka, and T. Uesugi, Appl. Phys. Express 10, 016501 (2016).

${ }^{22}$ B. N. Feigelson, T. J. Anderson, M. Abraham, J. A. Freitas, J. K. Hite, C. R. Eddy, and F. J. Kub, J. Cryst. Growth 350, 21 (2012).

${ }^{23}$ K. Shima, H. Iguchi, T. Narita, K. Kataoka, K. Kojima, A. Uedono, and S. F. Chichibu, Appl. Phys. Lett. 113, 191901 (2018).

${ }^{24}$ H. Iguchi, T. Narita, K. Kataoka, M. Kanechika, and A. Uedono, J. Appl. Phys. 126, 125102 (2019).

${ }^{25}$ R. Tanaka, S. Takashima, K. Ueno, H. Matsuyama, M. Edo, and K. Nakagawa, Appl. Phys. Express 12, 054001 (2019).

${ }^{26}$ H. Sakurai, M. Omori, S. Yamada, Y. Furukawa, H. Suzuki, T. Narita, K. Kataoka, M. Horita, M. Bockowski, J. Suda, and T. Kachi, Appl. Phys. Lett. 115, 142104 (2019)

${ }^{27}$ K. Iwata, H. Sakurai, S. Arai, T. Nakashima, T. Narita, K. Kataoka, M. Bockowski, M. Nagao, J. Suda, T. Kachi, and N. Ikarashi, J. Appl. Phys. 127, 105106 (2020).

${ }^{28}$ T. J. Anderson, J. D. Greenlee, B. N. Feigelson, J. K. Hite, F. J. Kub, and K. D. Hobart, ECS J. Solid State Sci. Technol. 5, Q176 (2016).
${ }^{29}$ M. J. Tadjer, B. N. Feigelson, J. D. Greenlee, J. A. Freitas, T. J. Anderson, J. K. Hite, L. Ruppalt, C. R. Eddy, K. D. Hobart, and F. J. Kub, ECS J. Solid State Sci. Technol. 5, P124 (2015).

${ }^{30}$ K. Kojima, S. Takashima, M. Edo, K. Ueno, M. Shimizu, T. Takahashi, S. Ishibashi, A. Uedono, and S. F. Chichibu, Appl. Phys. Express 10, 061002 (2017).

${ }^{31}$ A. Uedono, S. Takashima, M. Edo, K. Ueno, H. Matsuyama, W. Egger, T. Koschine, C. Hugenschmidt, M. Dickmann, K. Kojima, S. F. Chichibu, and S. Ishibashi, Phys. Status Solidi B 255, 1700521 (2018).

${ }^{32}$ A. Uedono, H. Iguchi, T. Narita, K. Kataoka, W. Egger, T. Koschine, C. Hugenschmidt, M. Dickmann, K. Shima, K. Kojima, S. F. Chichibu, and S. Ishibashi, Phys. Status Solidi B 256, 1900104 (2019).

${ }^{33}$ A. Kumar, J. Uzuhashi, T. Ohkubo, R. Tanaka, S. Takashima, M. Edo, and K. Hono, J. Appl. Phys. 126, 235704 (2019).

${ }^{34}$ W. Yi, A. Kumar, J. Uzuhashi, T. Kimura, R. Tanaka, S. Takashima, M. Edo, Y. Yao, Y. Ishikawa, J. Chen, T. Ohkubo, T. Sekiguchi, and K. Hono, Appl. Phys. Lett. 116, 242103 (2020).

${ }^{35}$ D. A. Muller, N. Nakagawa, A. Ohtomo, J. L. Grazul, and H. Y. Hwang, Nature 430, 657 (2004).

${ }^{36}$ P. J. Phillips, M. De Graef, L. Kovarik, A. Agrawal, W. Windl, and M. J. Mills, Ultramicroscopy 116, 47 (2012).

${ }^{37}$ D. A. Basha, J. M. Rosalie, H. Somekawa, T. Miyawaki, A. Singh, and K. Tsuchiya, Sci. Technol. Adv. Mater. 17, 115 (2016).

${ }^{38}$ F. R. Ding, W. He, A. Vantomme, Q. Zhao, B. Pipeleers, K. Jacobs, and I. Moerman, Mater. Sci. Eng. B 98, 70 (2003).

${ }^{39}$ H. H. Tan, J. S. Williams, J. Zou, D. J. H. Cockayne, S. J. Pearton, J. C. Zolper, and R. A. Stall, Appl. Phys. Lett. 72, 1190 (1998).

${ }^{40} \mathrm{~K}$. Lorenz, E. Wendler, A. Redondo-Cubero, N. Catarino, M. P. Chauvat, S. Schwaiger, F. Scholz, E. Alves, and P. Ruterana, Acta Mater. 123, 177 (2017).

${ }^{41}$ C. Liu, B. Mensching, K. Volz, and B. Rauschenbach, Appl. Phys. Lett. 71, 2313 (1997).

${ }^{42}$ C. Liu, A. Wenzel, K. Volz, and B. Rauschenbach, Nucl. Instrum. Methods Phys. Res. B 148, 396 (1999).

${ }^{43}$ M. A. Aronova, Y. C. Kim, G. Zhang, and R. D. Leapman, Ultramicroscopy 107, 232 (2007).

${ }^{44}$ S. Khromov, D. Gregorius, R. Schiller, J. Lösch, M. Wahl, M. Kopnarski, H. Amano, B. Monemar, L. Hultman, and G. Pozina, Nanotechnology 25, 275701 (2014). 